\title{
Discussion on Teaching Model of English Translation in Universities under Functional Translation Theory
}

\author{
Li Shao \\ Zhengzhou Institute of Technology \\ Zhengzhou, China
}

\begin{abstract}
As a symbol, language plays the role of medium in the process of communication. On connotation and value of language, it carries regional and national thinking habit and values. After translation theory changes from text to function, it pays attention to function application of language after translation. Functional translation theory that bases on target theory of translation decides principles and direction of translation and has guiding significance on optimization of translation effect. Functional translation theory meets the requirements of current social development for translation talents and has important guiding significance on English translation teaching in universities.
\end{abstract}

Keywords - functional translation theory; translation teaching; college English; symbolic philosophy

\section{INTRODUCTION}

Language is used by people with different thinking habits and cognition in different areas. In order to realize communication between different languages, translation theory constructs a series of guiding principles. There is no doubt that it puts textual norms in central position on guidance of theory. It pays high attention to the principle that the language after translation shall follow the principle of fidelity. In this situation, the language neglects the scene after translation, so the effect of communication is not obvious. Talents trained under guidance of this translation theory cannot meet requirements of social development. [1] In change of social environment, the functionalist school of translation theory is gradually valued. It takes essence from traditional translation theory, changes the defects on translation theory, combines multiple elements such as initiator of translation, translator, composer and receiver of translation together, aims at intended functions of translation and provides development ideas for universities in our country to cultivate practical talents of English translation.

\section{CONNOTATION AND CHARACTERISTICS OF FUNCTIONAL TRANSLATION THEORY}

Functional translation theory is mainly put forward by Katharina Reiss in Possibilities and Limitations of Translation Criticism. Afterwards, it forms a representative school: functionalist school, after being improved through development and continuous annotation of representatives of some translation theories. In the concept of functionalist school, it does not put origin of force of translation on transformation of text. [2] Text serves as main source of data of understanding and communication, but the culture carried by text is different. The purpose in accepting text may be different. Translation is to serve receiver. If it bases on the translated text without timely changing according to the environment, the effect of translation will be greatly discounted. Functional translation theory takes requirements of receivers into the process of translation and thinks text knowledge of translation provides information. In the process of translation, it needs to use related translation theories and translation skills to directly convey text essence of translation to receivers, which is the main purpose and function of translation.

Different from traditional translation theories, translation changes from rigid text to translation action of text. That is to say, it can convert to use translation skills of translators on behavior under the premise of ensuring authenticity of the original work. Because translators need to consider intention of initiator and willingness of receiver in translation, they must know about thoughts of principal parts and value guidance. The process of translation is to arrange these elements. [3] The requirement of functionalist translation theory for translation is to choose methods and strategies of translation according to objective guidance of translation. Translation action comes from purpose of translation, which translation purpose comes from real information of text. In translation, it shall be loyal to translated text. In the process of translation, it is necessary to consider functional objectives of translation, process and deal with information to keep the article after translation coherent and smooth.

\section{CURRENT SITUATION OF ENGLISH TRANSLATION TEACHING IN UNIVERSITIES}

In training of translation talents, universities carry out text teaching according to social needs and translation theories. Translation teaching mainly focuses on teachers, which guide students' text translation and improve students' translation skills. From the perspectives of overall educational pattern and effect of education, English translation teaching in universities fails to reach the standard. Although translation becomes a part of English teaching, the proportion of translation teaching differs according to different majors. Specifically speaking, the current situation of English translation teaching in universities is showed in the following aspects. 


\section{A. Theoretical Property of English Translation Is Not High}

The main mode of translation teaching in domestic universities is that teachers, the initiator of translation, choose materials that need translating from data bank for students, and then require students to complete the translation task within specific time through looking up some materials. [4] In teaching, teachers compare students' translation results with reference version of translation materials, find out the problems and explain it. It makes students practice repeatedly and continuously, so students can get certain translation skills, but lack theoretical research on translation. Translation theory is scientific guidance of translation. The sentences, gist of a paragraph and integral value inclination of the article have clear standard. If teachers explain under the premise of lacking theory, the translation will be of low quality. In English translation education, translation will not be able to combine with theory in practice and highlight the color of theory.

\section{B. Methods of English Translation Teaching Are Unscientific}

English translation teaching lacks the guidance of theory, so the teaching methods are unscientific. English translation teaching follows traditional teaching methods, starts with the text of teaching and pays attention to decomposition and analysis of text. Text is the important information of translation, but it can only reflect representation of thoughts. It also needs to integrate related historical background to go into the thoughts of text seriously. In English translation, it is important to understand author of the original work. However, because of different teaching methods, the understanding of author of the original work is different, too. [5] The teaching method is teacher-centered. One teacher teaches many students and the whole teaching centers on teachers. The thoughts and values of teachers are only unique parts of it. Therefore, students receiving English translation teaching are influenced by teachers to a large extent and lack thinking of their own in translation.

\section{English Translation Teaching Neglects Cultural Backgrounds}

The difference of language not only shows on language forms. We can only distinguish the difference represented by different symbols from different expression forms of the same thing, but it is impossible to grasp thoughts and values in the back of language. Thinking habits and value idea lead to different translation. In English translation teaching in universities, the lack of cultural backgrounds leads to the situation that the connotation of translated works is not enough. In English translation, the neglect of cultural backgrounds is easy to lead to localization of translation. That is to say, the text of translation is understood on the basis of local thinking, but in fact, it may be of great differences. [6] If translated text has relatively strong comprehensiveness, rich cultural contents and high specialty, but does not combine with related cultural knowledge, it cannot reach the romantic charm of translation. At present, for the introduction of cultural backgrounds in English translation teaching, some universities do not arrange enough class hours. Besides, students cannot feel cultural backgrounds in practice. It is also a problems existing in English translation teaching.

\section{ENLIGHTENMENTS BROUGHT BY FUNCTIONAL TRANSLATION THEORY FOR ENGLISH TRANSLATION IN UNIVERSITIES}

Functional translation theory attaches importance to functional objectives of translation instead of text, which highlight the importance of translation effects. It makes the translation from simple explanation of words and sentences to emotional language expression. Functional translation theory brings new development ideas for English translation teaching. At the meantime, new development theory will also promote the transformation of English translation in universities and make it present the effects of expression to the largest extent.

\section{A. Make the Purpose of Translation Clear and Emphasize Functionality of Translation}

Translation can break through the barriers of two different cultures, transform pattern of manifestation of culture and then achieve communication between cultures. Different from traditional translation theories, functional translation theory makes the purpose of translation clear in guiding translation, starts with the objects that receive the translation and then makes the translation meet requirements of readers. In translation of works, function translation pays attention to the purpose, coherence and fidelity of translation and bases on the purpose of translation in choosing translation strategies. [7] Translation is the communication and mutual intelligibility of two cultures. Every person has different understanding for culture. In addition, because translators exist in translation of works, if the purpose of translation is unclear, the translation result will be different. Meanwhile, the result of translation is to serve people. If we do not emphasize functionality in translation but translate according to the text, the translated works will not have social effects.

\section{B. Pay Attention to Cultural Thinking of Translators}

Paying attention to cultural thinking of translators is the important part emphasized by functional translation theory. The translation of works is not simple replacement of formula and merging of the same kinds. It has internal conflicts. The definition of culture is abstract, so it is difficult to see it on the surface of translated works. Paying attention to cultural thinking of translators is to put translators on the path formed by culture and makes readers understand culture well. The emphasis of functional translation on cultural background is also to better meet requirements of readers in translation and be faithful to the original works. Paying attention to cultural thinking can avoid errors in literal translation for words and reduce misunderstanding for related backgrounds in works under different environments.

\section{Change the Standard of Translation}

In English translation teaching of universities, the evaluation of final translated works mainly bases on standards provided by teachers. The standard answers of teachers become main basis of translation. Translation can get different 
translation effects from different perspectives. Standard answer is to fix certain translation results through outside enforcement. Therefore, the translation can only base on this standard to evaluate whether it conform to the standard. Instead of fix the standard of translation in standard reference version, functional translation theory gives the decisionmaking power to readers and sees whether the translation conforms to the standard or not according to response from readers. In teaching, it needs teachers and students to discuss the translation together and choose the translation jointly recognized by the public as the best normal form.

\section{Pay Attention to Training Initiative of Students}

Functional translation theory thinks that before translation, teachers need to set anticipated translation effects according to materials that needs translating, introduce the background and purpose of translation to students. Students look up related materials through independent learning and carry out English translation. Many knowledge and skills involved in English translation need students to learn. Firstly, it is grammar in English translation. In translation teaching, students need to actively specialize in English grammar and compare the difference and make efforts to realize "faithfulness, expressiveness and elegance" in translation. [8] Secondly, students need to actively read a large number of books after class to widely know about English culture. Because at the beginning of translation, functional translation theory has set the purpose of translation, students only need to actively think in translation according to the purpose instead of passively listening to the teachers.

\section{STRATEGIES OF ENGLiSh TRANSLATION TEACHING IN UNIVERSITIES UNDER FUNCTIONAL TRANSLATION THEORY}

Different from traditional translation modes, in English teaching, functional translation theory emphasizes the practicality of translation, makes translation reach the anticipated function, which will improve current situation of English teaching and improve the quality of English translation teaching. In order to apply functional translation theory in English translation teaching of universities, it can start with the following examples thinking.

\section{A. Teachers Choose Reasonable Teaching Materials of Translation}

The selection of translation materials shall conform to physical truth of students' learning. That is to say, teaching materials of translation meet students' actual translation level. If too high, it is difficult for students to translate; if too low, it will influence students' emotions in translation. Therefore, proper degree of difficulty of translation can bring students new knowledge as well as stimulate stronger interest of students to learn. When choosing reasonable teaching materials of translation, teachers shall base on teaching arrangement. In particular, the teaching materials of translation need to be coherent to make the knowledge learnt by students form a system in the end.

\section{B. Formulate Standard Translation Outline}

In English translation teaching, teachers are only the initiator of translation. When asking students to translate materials, teachers need to show the purpose of translation, anticipated effect of translation and requirements of translation to students, make use of the effect of anticipated purpose in functional translation theory to guide the translation of students. The translation outline shall bee standard to standardize students' behaviors on the whole.

\section{Analyze the Original Text through Interaction between Teachers and Students}

Functional translation theory pays attention to the analysis on original text. Under the premise of determining translation outline, the analysis on translation can make teachers and students know about cultural backgrounds related the original text. Teachers and students can absorb knowledge and experience together and deep the understanding for culture. The interaction between teachers and students not only shows in analysis on the original text but also shows in analysis and evaluation on translation. Because functional translation puts the realization of function in the first place, teachers and students can choose the translation with the best expression effects through analysis.

\section{References}

[1] Mao Zhihong. College English Teaching Innovation under Functional Translation Theory [J], Modern Communication, 2012(11): 37-38.

[2] Xie Yanhong. Application of Functional Translation Theory in College English Translation Teaching [J], Journal of Luoyang Normal University, 2010(04): 19-20.

[3] Ding Hongzhao. Business English Translation Teaching on the Basis of Functional Translation Theory [J], Journal of Educational Institute of Jilin Province (Subject Edition), 2010 (08): 46-47.

[4] Huang Yonghong. Discussion on Enlightenment of Functional Translation Theory on College English Translation Teaching [J], China out of School Education, 2010(04): 98-99.

[5] Ni Xiaoshan. Analysis on Strategy of News Translation from Chinese to German on the Basis of Functional Translation Theory [J], News Research Guide, 2016 (06): 73-74.

[6] Li Guang. Exploration of Functional Translation Theory on College English Translation Teaching [J], English on Campus, 2016(08) : 27-28

[7] Xiao Meng. Exploration on Translation Teaching Mode in Foreign Language Specialty in Universities of Our Country under the Guidance of Function Translation Theory [J], Journal of Yunnan University (Social Science Edition), 2010(04): 57-58.

[8] Li Ting. Exploration and Analysis on English Translation Skills under the Viewpoint of Functional Translation Theory [J], English Square (Academic Research), 2013(02): 63-64. 